\title{
Russian banking system: searching for trust
}

\author{
Marina Bogatyreva ${ }^{1, *}$, Aleksandr Kolmakov ${ }^{1}$, and Mikhail Kolmakov ${ }^{2}$ \\ ${ }^{1}$ Irkutsk National Research Technical University, 664074, Lermontov str, 83, Irkutsk, Russia \\ ${ }^{2}$ Irkutsk Branch of the Russian Academy of National Economy and Public Service, 664003, \\ Kommunarov str., 10, Irkutsk, Russia
}

\begin{abstract}
The article is devoted to the study of trust, as an economic resource, contributing to the reduction of transaction costs. The paper is divided into two parts. In the first part, the authors define trust, as the transaction participants' conviction that they can rely entirely on the counterparties' promises. After that, the character of the damage that the society experiences from the disappearance of the relationship of trust is determined. These losses are caused by the switching of resources from the productive area to the scope of transaction management. Then the authors formulate the conditions that are necessary for the emergence of trust as such and for its spread in the Russian economy. There are two such conditions. The first is the impossibility of changing the contract unilaterally, without taking into account the interests of the counterparty. The second condition is the ability to control the execution of the transaction at any time by the counterparty. Later, the authors set out the reasons why trust has not spread in the political and economic life of contemporary Russia. The second part of the article explores the specific economic problems that arise in connection with the lack of trust between the parties to the contract. As an example, the banking sector, that is, perhaps the most important branch of the modern economy is considered. The second part begins with a short historical overview of the development of the banking sector of modern Russia. It is noted that real interaction between commercial banks and the Russian households began only in the $21^{\text {st }}$ century, when the ruble exchange rate stabilized and the household incomes began to grow rapidly. At the same time, the practice of opportunistic behavior of commercial banks in relation to households was formed. This practice manifests itself in the systematic provision of false information to the customers or withholding truthful information from them. The opportunism of banks, along with high real interest rates, has caused the extremely small role played by Russia's banking system in shaping consumer demand and, accordingly, overcoming the economic crisis. The passive position taken by the Bank of Russia in confronting banks and households is noted.
\end{abstract}

\footnotetext{
*Corresponding author: bmw2005@ list.ru
} 


\section{Trust as an economic resource}

This article contains some new hypotheses regarding the formation of trust relationships in the economy of modern Russia. By that, the authors continue the cycle of publications, which began about ten years ago.

Trust is what we call specific relations between the transaction participants, which are characterized by the fact that the parties rely on simple promises of the counterparty. The term "simple promises" means that pledges of a material nature, for example, such as prepayment or provision of property, are not provided as a guarantee for the performance of a transaction. The value of trust is that it allows significantly reducing the level of costs for the contract management, that is, the transaction costs. It is this property - a significant saving of limited public resources - that allows us referring trust itself as the category of valuable economic resources.

The reality is that confidential relations occupy an insignificant share in the space of economic relations of the Russians. This means that a significant amount of resources available to economic agents cannot be used in a productive way. To answer the question about the reasons for the lack of trust, it is necessary to recall the conditions that in principle (in the opinion of the authors) contribute to the formation of trust.

There are three such conditions. Firstly, this is the basic condition of any contract - the independence of counterparties from each other. The second factor is the ability of each party to check the counterparty's commitment to the transaction at any time, its, so to speak, sincerity. The third factor is the equality of the parties of the contract, that is, the impossibility for each party to change the terms of the contract unilaterally.

Competition is the most effective mechanism ensuring the fulfillment of all these conditions. Availability of a set of equivalent alternatives does not leave the buyer or seller opportunities for "the opportunistic behavior". Any attempt to deceive the counterparty will immediately lead to the termination of the transaction and the loss of all the benefits from it. Of course, we are considering the transaction between the parties as not an isolated case, but as a continuous contract process. The presented model, in which competition is the main condition for building trust, is purely theoretical. The actual markets that we observe in everyday life are rich in deviations from the presented model. And practically all these deviations make it difficult to form the trusting relationship. Suppose, for example, that for some reason the seller believes that he will no longer come into contact with this buyer. Then he has absolutely no risks of loss of reputation, because reputation can be formed only as a result of a series of contracts. In this case, nothing, except strong religious or moral restrictions, prevents the seller from embarking on the path of opportunism, that is, simply deceiving the buyer. The probability of such a development of events the greater, the less important role is played by the "informed buyers" on this market. In turn, the role of informed buyers can be explained either by communication difficulties or by the fact that the seller has the ability to mimic, that is, to change those parameters of his activity that the buyer reads. The opportunism of the particular seller exerts a tremendous influence on the entire market, since its (seller's) activity is associated with a reputational external effect. It means that the deception of just one seller in the extreme case can lead to total mistrust of buyers in relation to all sellers on this market.

The model of the optimal household consumption can illustrate the results, to which leads a lack of trust between the participants in the transactions (Figure 1). First, suppose that the market is dominated by the trusting relationship. The household is in the situation of choice between keeping a stock of money (M) in its hands, and acquiring a certain amount of consumer goods $(\mathrm{G})$. It can change the whole stock of money $\left(\mathrm{M}_{0}\right)$ for the consumer goods. Then the volume of consumption will be $\mathrm{G}_{0}$. Either the household mixes in its wealth the consumer goods and services with some remaining money. These sets can be composed in 
any proportion. Thus, we get the budget line $\mathrm{M}_{0} \mathrm{G}_{0}$. The household chooses a set $\alpha$, which brings to it the maximum (at given prices and the reserve of money) utility

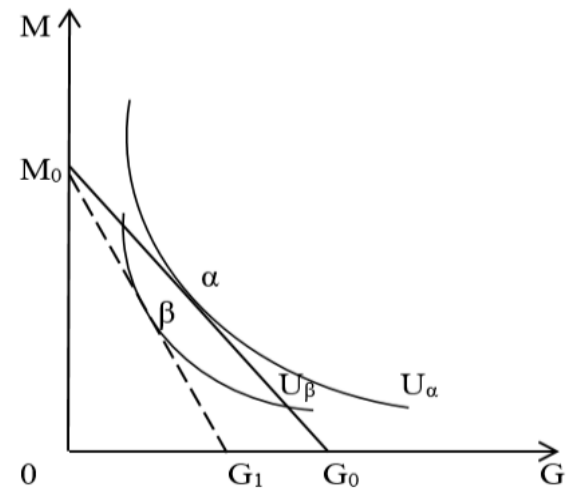

$\mathrm{U} \alpha$.

Fig. 1. Change in the wealth of a household in the case of disappearance of trusting relationships.

Now suppose that the trust relationship has disappeared. Then the household is forced to spend part of the resources to make sure the sincerity of the offer from the sellers. These resources do not add anything to the welfare of the household; they are simply absorbed in the transaction. The situation is exactly the same as if the price of goods and services purchased by the household increased. The rise in prices, as we know, leads to a turn of the budget line around point $\mathrm{M}_{0}$ counter-clockwise. Now the budget constraint is described by the line $\mathrm{M}_{0} \mathrm{G}_{1}$. Under the new restrictions, the household will choose the set $\beta$, which lies on the lower indifference curve U $\beta$. It means that now the household gets less benefit. Thus, we made sure that trust is a valuable resource, the lack of which leads to a decrease in the welfare of the household and society as a whole.

Now let us return to our model of competition, as an instrument that fosters trust. Needless to say, the assumption of the "equivalence of alternatives", to which market supporters so often refer, does not always correspond to reality? As soon as assets that are commonly referred to as "specific" become the object of the transaction, then immediately the relationship between the seller and the buyer ceases to be cloudless. The problem is that specific assets on the market can be offered by a few sellers that allow them influencing the terms of the transaction even after the contractual mechanism is activated. This possibility of one of the parties to change the terms of the deal unilaterally, redistributing, of course, the benefits of the contract to its own advantage, has the most destructive consequences for the existence of a trust relationship. Therefore, communities consisting of rational individuals are trying to develop mechanisms that prevent the most harmful forms of opportunism. For example, residual control rights belong to such mechanisms. Actually, all the systems of contract law exist precisely in order to reduce the costs of contract management. And although in practice the vast majority of contract disputes are resolved to bargain participants without recourse to the third parties, this should not deceive us, as "contract relations always develop in the shadow of the law".

It is very important that each party of the contract has tools to ensure effective control over the actions of the other party. Once such tools disappear, the trust between the parties also disappears. However, options are possible. Let us give an example that, at first glance, is far from the economy. In 2015 and in 2016, the Prime Minister of Russia D.A. Medvedev made three very important decisions. First, he refused to index pensions in accordance with actual inflation (12\%) and indexed them in accordance with the assumed level of inflation (4\%). Secondly, he refused to index pensions to working pensioners according to the same 
scheme by which the pension is indexed to non-working pensioners. Finally, he fundamentally revised the indexation of pensions, tearing them away from the real participation of the employee (through the employer) in the replenishment of the pension fund. All three measures were clearly fiscal. By these decisions, the social contract concluded between the pensioners and the authorities a few years earlier was actually disavowed. Thus, we observe a classic case of the opportunistic behavior - one of the parties of the contract arbitrarily revised it to the detriment of the interests of the other party. However, these decisions only triggered a procedure for the revision of the contract. After all, in the hands of the population remained a powerful instrument of the residual control that is the right to vote in the parliamentary elections. With its help, the population could give a very clear signal that it was not satisfied with the Prime Minister's policy. Then, it is quite possible, the social auction would resume. However, extreme conservatism in the political preferences of the Russians prevented them from using this tool. The results of the vote unequivocally testified the support of the course of the Prime Minister - the party headed by him received $76 \%$ of the votes to the State Duma.

The most interesting thing is that surveys conducted regularly among the population show that confidence to the Government remains at a very low level. Rather, we can talk about distrust, than about trust. This distrust is a natural result of the fact that the population does not control the behavior of its counterparty in the transaction (which is the Government). The only paradox is that in reality the population can control the behavior of the other party of the contract, but does not know how to do it.

\section{The Russian banking system: the experience of transactions without trust}

At the onset we have to make a reservation that out of all the intricacies of relations within the Russian banking sector and in its interaction with the rest of society, we have chosen only those fragments where the absence of trust is manifested in the especially clear way.

Russia's two-tier banking system has existed for more than a quarter of a century. At the very beginning of the journey, there were over 3,000 banks in it, which mostly earned on the negative real interest rates. In the $20^{\text {th }}$ century, lending to the private sector of the economy could not compete in its profitability with the operations in the financial sector and in the foreign exchange market. Russian commercial banks were often engaged in exotic operations, which went beyond the limits laid down by the criminal law. Suffice it to recall Sodbiznesbank, which license was withdrawn in the spring of 2004 with the formula "for financing terrorist activities".

The situation began to change at the beginning of the $21^{\text {st }}$ century. Stabilization and subsequent strengthening of the ruble led to a decrease in the profitability of foreign exchange transactions. At the same time, rapid economic growth and rising incomes of the population turned bankers towards the real sector of the economy. The fact that the rate of inflation stabilized near $10 \%$ also played its role.

In this period, consumer lending was the driver of growth in the banking sector of the economy. This scenario was quite natural. Firstly, a sharp increase in imports generated a wave of consumer effects. Secondly, for the first time in life of many generations, the barrier, known as "the liquidity limitation", was overcome. In other words, the Russians gained an access to the financial market. Thirdly, the real incomes of the Russians grew quite rapidly and for a long time that could not but inspire confidence of people in their future. Finally, it cannot be discounted that the level of financial literacy of the Russians was, and still remains at a very low level, at such a level that they cannot even calculate the real interest rate on the loan. All these predetermined the unusually high profitability of this type of business, such as consumer lending. 
There came a period when, for the second time in the years of market reforms, the broad strata of the population could feel, roughly speaking, "the advantages of capitalism". The first time it happened in the very beginning of the 1990s, when price liberalization almost instantly filled the shelf of shops that had been empty under socialism, with goods. Commercial banks could choose a manner of behavior that would lay the foundation for the emergence and spread of trust in the entire Russian economy. For this, they simply had to pursue an honest and transparent policy in relations with their compatriots. Unfortunately, the Russian banking sector did not live up to its expectations. Greed won, the desire to get maximum profit, and commercial banks began to fool their customers in eager rivalry, either by simply deceiving them, or by hiding truthful information from them. Great was the disappointment of people and their resentment, when the terms of the loans turned out to be times heavier than they thought at the time of signing the contract.

It is clear that stating the fact that Russian commercial banks have chosen a "predatory model" of behavior does not advance us academically. On-good, we are obliged to identify the reasons why the banking community behaved this way, and not otherwise. A fundamental study of these issues is still to be completed. Here we can only point out the most common causes of universal banking opportunism.

Apparently, we cannot escape anywhere that Russia inherited from the USSR not only economic assets, but, so to speak, the human capital. In this cultural "wealth" of a personality, his individuality was given a small place. This disparaging attitude toward man, formed in the USSR, preserved like a relic radiation. When the economy began to acquire market characteristics, these disparaging relations were filled with new content - it became possible, in economic terms, to coin a sense of the intellectual superiority over the counterparty.

At a time when the consumer lending boom was only beginning, customers of commercial banks could rely on the state assistance in defending their rights. The interests of clients were defended by three institutions - the Federal Antimonopoly Service (FAS), the Federal Service for Supervision of Consumer Rights Protection (Rospotrebnadzor) and the Bank of Russia. Initially, the efforts of these services were aimed at ensuring that information on the real (effective) interest rate on the loan was necessarily communicated to customers. There has been a long struggle between supervisors and commercial banks, during which commercial banks have shown that the opportunism in relations with the customers is the norm of their behavior.

Initially, the federal services achieved some success. For example, they have achieved the cancellation of such a duty of clients, as "the fee for opening and maintaining a loan account". Then the law was passed, according to which banks were required to write the effective interest rate in the text of the loan agreement. Banks fulfilled these requirements formally, indicating the percentage in a small font. The services had to amend the legislation to prohibit banks from masking the real interest rate in the text of the contract. Then banks switched to a new strategy. They did not disclose the real interest rate to the client during the whole process of the loan negotiations. Instead, they reported the information that did not allow customers to get an idea of the real interest rate. They said, for example, about the "value of the monthly payment" or about the "total amount of overpayment". Federal services could not oppose this policy because their ability to monitor the behavior of commercial banks was very limited. The problems of building trust between the banking sector and the private sector of the economy (with the exception of the corporate sector) went into the shade only during the financial crisis of 2008 and the next two years. It happened for purely technical reasons.

The main result of the confrontation between commercial banks and federal structures defending the interests of clients was that, in order to maximize profits in a short run, the banking sector always found opportunities to circumvent the requirements of legislation and continue its openly opportunistic policies towards the clients. It was mainly explained by the 
lack of the means for effective monitoring of banking policy at the disposal of the regulatory bodies.

As soon as commercial banks, according to R. Koo, "cleared their balance sheets after the financial crisis", the instinct to profit maximization returned to them, and they went back to the policy they "preached" before the crisis, that is, to open opportunism. It was mostly evident in the area of interest rates on loans granted to the households and firms not affiliated with the state. In the end, the problem of protecting clients from unscrupulous policies of commercial banks reached the level of the Parliament. Under the pressure of the State Duma, the Bank of Russia decided to impose "maximum interest rates" on the main types of lending to the population. The validity of such measures is traditionally questioned within the framework of the economic theory, since bureaucratic interference in the operation of the price mechanism leads to inefficient use of limited public resources. In this case, the matter was aggravated by the fact that the Bank of Russia had no effective instruments to monitor compliance with the regulator's recommendations by commercial banks. (The inclination to use administrative methods of management in the banking sector did not serve well to the Bank of Russia in the field of supervision of the deposit policy of commercial banks. Here, as in the field of lending, the limit values were set for the interest rates, at which commercial banks could attract loans from the population without incurring the anger of the Bank of Russia. It is clear that by attracting deposits at higher rates, commercial banks took on an increased risk. However, as shown by the experience of consumer lending, private commercial banks use financial resources much more efficiently than banks with the state participation, located at the top of the banking sector. Therefore, they could afford to attract deposits at higher interest rates. By the way, they thereby sent a signal to the Bank of Russia about their more risky policy. Having lost the opportunity to officially maneuver with deposit rates, some commercial banks "went underground", and began to engage very exotic operations. When the problems of these banks (Master-Bank, Mosoblbank) came out, the size of the household losses was already hundreds of billions of rubles. It is needless to say about the loss of reputation of the whole banking community, which was the result of such fraud of its individual members).

However, the decrease in the effectiveness of protecting customers from unfair behavior of commercial banks is due not only to monitoring difficulties. We have to admit that recently the priorities in the policy of the Bank of Russia have changed. After the financial turmoil that occurred in December 2014, the Bank of Russia management officially recognizes that the main priority for the Bank is the stability of the Russian banking system. On this road, the Bank of Russia has achieved notable successes. But these successes were paid for by a high price. The main thing is that the Russian banking system has lost its instrumental value. To put it simply, Russia's banking system is in excellent condition, but it is not used as a mechanism capable of increasing aggregate demand. To verify that, it is sufficient to review the data in the Table 1.

Such a low share of loans that banks gave to the households can be explained by several reasons. Unusually high interest rate is, certainly, at first place. The strategy of maximizing profits in a short period has led commercial banks to a standstill. Those customers who used to take loans, regardless of the interest rates, are now burdened with the debts of the past periods and withdrew from the game. The remaining clients soberly assess their financial capabilities and do not agree to take loans at current interest rates. It seems that commercial banks have no other option than competitive betting. But so far banks prefer to stick to the old strategy. 
Table 1. Dynamics of the debt burden of the Russian households.

\begin{tabular}{|c|l|c|c|c|}
\hline \multicolumn{2}{|c|}{} & \multicolumn{3}{c|}{ Year } \\
\hline № & \multicolumn{1}{|c|}{ Indicator } & 2015 & 2016 & 2017 \\
\hline 1 & Household loans (billion rubles) & 11647.1 & 11757.5 & 13168.7 \\
\hline 2 & GDP (billion rubles) & 83387.2 & 86148.6 & 92037.2 \\
\hline 3 & Debt burden (2/3) (\%) & 14.0 & 13.6 & 14.3 \\
\hline
\end{tabular}

It cannot be said that commercial banks do not react in any way to the current situation. For example, they began to pay much more attention to the customers who proved their respectableness for many years of serviceable payments. However, contrary to the rules of a market economy, attention is not accompanied by the price signals in the form of a lower interest rate. As before, the customer's credit history did not become a trump card in the package of documents that banks require to secure a loan. It did not even displaced any documents from those that were required before the appearance of credit histories. Refusals to radically reduce the interest rate, commercial banks are trying to compensate with even more sophisticated opportunism. Even if they achieve local success, then this will not radically affect the situation with the freezing consumer demand.

The second reason is a stock of mistrust accumulated by the Russians over a decade and a half of close interaction with commercial banks. The reality is that the authors of this article did not find any sincere proposal forwarded by commercial banks to their clients during the field research conducted in October 2017. It applies to the full range of services provided. The Scots say that three things should be feared: the horse's hooves, the horns of the bull, and the smile of the Englishman. The Russian specificity consists in the fact that instead of an Englishman one should be afraid of "a favorable offer" from a commercial bank.

Competition between banks could help the business. However, competition between the Russian banks in a strange way did not lead to the disappearance of opportunism. Moreover, those commercial banks that used to be known for their good behavior towards their clients, quickly discovered that honesty is not in the credit. The bank VTB-24 is an example. Such a result of the competition can be explained only by the presence of a powerful external effect accompanying the activities of a commercial bank.

The Bank of Russia could play a crucial role in restoring and developing trust relationships. But, as mentioned above, now it has other priorities. When the stability of the banking system is at first place "at any cost", eyes can be closed to the dishonesty of banks with respect to the households. In the end, opportunism allows commercial banks making high profits, which is exactly what the Bank of Russia management needs now. If the Bank of Russia revoked licenses from commercial banks not only for direct deception of the households, but even for trying to hide some of the information from them, as it is now revoking licenses for providing unreliable reporting, then it seems to us that confidence in the banking sector of economy would be restored fairly quickly. And along with this, the volume of lending would also increase, which is so necessary for the Russian economy in these difficult times.

\section{References}

1. A. Greenspan, The epoch of shocks: problems and prospects of the world financial system (United Press, Moscow, 2010)

2. A. E. Kolmakov, M. V. Bogatyreva, Rationality, trust, and transaction costs (Izd-vo IrSTU, Irkutsk, 2014)

3. $\mathrm{R}$. $\mathrm{Ku}$, The holy grail of macroeconomics: lessons from the Great Japanese Recession (Thought, Moscow, 2014) 
4. M. Lewis, Boomerang: travels in the new third world (Alpina Pablisher, Moscow, 2015)

5. D. Tobin, Financial intermediaries (Infra-M, Moscow, 2004)

6. O. I. Williamson, Economic institutions of capitalism: firm, markets, "relative" contracting (Lenizdat, CEV Press, St. Petersburg, 1996)

7. E. Hansen, Monetary theory and financial policy (Case, Moscow, 2006)

8. O. D. Hart, Incomplete contracts and firm theory (Case, Moscow, 2001)

9. J. Tobin, Kredit and Kapital, 16(2), 155-171 (1983) 